dependent upon it. Happily the country is now beginning to realise the importance of the matter, and when the Government places at the disposal of the Board sufficient money to carry on the necessary investigations, the produce of the Scottish fisheries, great as it now is, may be still largely increased.

\section{RADIANT MATTER SPECTROSCOPY}

TIIE following paper on this subject was read by Mr. Crookes at the Royal Society, June I8:--

In the concluding sentence of the Bakerian lecture which I had the honour to deliver before the Royal Society, May 3I, I 883, I said that the new method of radiant matter spectroscopy there described had given me not only spectrum indications of the presence of yttrium as an almost invariabl-, though very minute, constituent of a large number of minerals, but had likewise revealed signs of another spectrum-yielding element. I stated that I had repeatedly seen indications of another very beautiful spectrum characterised by a strong red and a double orange band.

Elimination of Mercury Vapour from Vacuum Tubss.--It is much more difficult than is generally supposed to keep mercury vapour from cliffusing into the experimental tubes.

The following plan answers perfectly so far as my experiments have yet gone:-Sulphur is first prepared by keeping it fused at a high temperature till bubbles cease to come off, so as to get rid of water and hydrogen compounds. It is then allowed to cool, and is pounded and sifted so as to get it in the form of granules averaging a millimetre in diameter. A glass tube, a centimetre in diameter and about 2 feet long, is lightly packed for half its length with this sulphur, and next about 2 inches of iodicle of sulphur $\left(\mathrm{I}_{2} \mathrm{~S}_{2}\right)$ is added, and the rest of the tube is then filled up with sulphur. Ignited asbestos is packed in at each end to keep the sulphur from blowing out whilst the vacuum is being made, or from being sucked through when air is suddenly let in. This contrivance entirely keeps mercury vapour from passing through, since the iodide of sulphur holds its iodine very loosely, and fixes the mercury in the form of nonvolatile red iodide. A glass tube containing finely-divided copper must follow in order to keep the sulphur out. With this blockade interposed between the pump and experimental tubes I have been unable to detect mercury vapour in any of the tubes, whether in the cold or on heating them.

The "Orange Band" Spectrum. - Since the date of my last paper I have devoted myself to the task of solving the problem presented by the double orange band first observed in I88I. With the yttrium experience as a guide it might be thought that this would not be a clifficult task, but in truth it helped me little beyond increasing my confidence that the new, like the old spectrum, was charactcristic of an element. The extreme sensitiveness of the test is a drawback rather than a help. To the in xperienced eye one part of "orange band" substance in ten thousand gives as good an indication as one part in ten, and by far the greater part of the chemical work undertaken in the hunt for the spectrum-forming element has been performed upon material which later knowledge shows does not contain sufficient to respond to any known chemical test.

Chemistry, except in few instances, as water-analysis and the detection of poisons, where necessity has stimulated minute rescarch, takes little account of "traces ; "and when an analysis adds up to $99^{\circ} 99$, the odd o or per cent. is conveniently put down to "impurities," "loss," or "errors of analysis." When, however, the $99^{\circ} 99$ per cent. constitutes the impurity and this exiguous $0^{\circ} \mathrm{Or}$ is the precious material to be extracted, and when, moreover, its chemistry is absolutely unknown, the difficulties of the problem become enormously enhanced. Insolubility as ordinarily unclerstood, is a fiction, and separation by precipitants is nearly impossible. A new chemistry has to be slowly built up, taking for data uncertain and deceptive indications, marred by the interfering power of mass in withdrawing soluble salts from a solution, and by the solubility of nearly all precipitates in water or in ammoniacal salts, when present in traces only. What is here meant by "traces" will be better understood if I give an instance. After six months' work I obtained the earth didymia in a state which most chemists would call absolutely pure, for it contained probably not more than one part of impurity in five hundred thousand parts of didymia. But this one part in half a million profoundly altered the character of didymia from a radiant matter spectroscopic point of view, and the persistence of this very minute quantity of interfering impurity entailed another six months' extra labour to eliminate these final "traces," and to ascertain the rcal reaction of didymia pure and simple.

Chemistry of the Orange Band-forming Substance.-At first it was necessary to take stock, as it were, of all the facts regarding the supposed new substance, provisionally termed $x$, which had turned up during the search for the orange band. In the first place $x$ is almost as widely distributed as yttria, frequently occurring with the latter earth. It is almost certainly one of the earthy metals, as it occurs in the insoluble oxalates, in the insoluble double sulphates, and in the precipitate with ammonia. It is not precipitated by sodic thiosulphate, and moreover it must be present in very minute quantities, since the ammonia precipitate is always extremely small, and as a rule $x$ is not found in the filtrate from this precipitate.

At this stage of the inquiry the chemical reactions of $x$ were much more puzzling than with yttria. At the outset an anomaly presented itself. The orange band was prone to vanish in a puzzling manner. Frequently an accumulation of precipitates tolerably rich in $x$ was worked up for purposes of concentration, when the spectrum reaction suddenly disappeared, showing itself neither in precipitate or filtrate ; whilst on other occasions, when following apparcntly the same procedture, the orange band became intensified and concentrated with no apparent loss. The behaviour of the sulphate to water was also very contraclictory ; on some accasions it appeared to be almost insoluble, whilst occasionally it dissolved in water readily.

Is " $x$ " a Mixture? - A very large series of experiments, which need not here be described in detail, resulted ultimately in establishing the remarkable fact that the $x$ I sought was an earth which of itself could give no phosphorescent spectrum in the radiant matter tube, but became immediately endowed with this property by admixture with some other substance, which substance likewise by itself had no power of phosphorescing with a discontinuous spectrum.

" $x$ " in Cerite.-In the corresponding yttrium research I was aided materially by the fact that the sought for earth did not give an absorption spectrum. This enabled me to throw out a large number of obscurely known clements, and I therefore early endeavoured to ascertain whether the supposed new earth, $x$, did or did not give an absorption spectrum. Gradually it was noticed that whenever the didymium absorption bands were strong, the orange band spectrum was also particularly brilliant. Moreover, amongst the earths previously cnumerated as mixed with lime in the quest for $x$, I have mentioned that some of them gave the orange band spectrum with increased intensity; the earths of the cerium group were the most noteworthy, and these considerations made it probable that here would be found the location of $x$.

Analysis of Cerite. - The cerium group consists of cerium, lanthanum, didymium, and samarium.

The first necessity was to get the earths ceria, lanthana, and the mixture hitherlo called dillymia, in a purc state; for my socalled pure earths of this group all showed the orange band in more or less degree.

The separation from each other of ceria, lanthana, didymia, and samaria is a most laborious process, and the amounts of these earths, obtainable in anything like a pure state, is small, compared with the mass of material worked up. Full particulars are given in the paper as to the method adopted to obtain each of them in a state of purity.

Ceria.-The ceric oxide obtained was almost pure white, A considerable thickness of a strong solution did not show a trace of absorption spectrun. The atomic weight of the metal was taken and yiclded the number $\mathbf{I} 4 \mathrm{I}^{\prime} \mathrm{r}$.

The ceric oxide gave no orange band spectrum in the radiant matter tube, either with or without the addition of lime.

Lanthana.-Lanthana is more difficult to purify than ceria. Long after the lanthana appeared pure it gave in the radiant matter tube a good orange band spectrum when mixed with lime and treated as usual, although without lime it gave no spectrum. Ultimately, however, a lanthana was obtained which, mixed with lime and treated in the usual manner, gave no orange band spectrum whatever. This lanthana was snow-white, and had. an atomic weight of 138.3 .

Didymia. - The earth formerly called didymia is now known to be a mixture of didymia and samaria, and systematic operations were now commenced with the object of obtaining the didymia and the samaria in a state of purity-that is to say, in such a condition that one of them should show no orange band 
spectrum at all, whilst the other should give the spectrum in its highest degree of intensity.

I commenced the purification of didymia in the latter part of the year 1883 , and the operations have been going on since almost daily in my laboratory. At intervals of some weeks the didymia in the then stage of purification was tested in the radiant matter tube, a little lime having previously been added to bring out the discontinuous phosphorescence. During the first month or two the intensity of the orange band spectrum scarcely diminished. After this it began to fade, but the last traces of orange band were very stubborn, and not till the last few weeks could I obtain a didymia to show no trace of the orange band spectrum ; and this result has not been accomplished without sacrifice. My Iooo grammes have dwindled away bit by bit, till now less than half a gramme represents all my store.

Samaria.-The foregoing experiments left little doubt that $x$, the orange-band-forming body, was samarium ; the last problem was, therefore, to get this earth in a pure state. The general plan of operations was the same as I adopted in getting didymium free from samarium, only attention was now directed to the portions richest in samarium which had been formerly set aside. The colour of samaria, as pure as I have been able to prepare it, is white with the faintest possible tinge of yellow. The absorption spectrum of samarium salts is much more feeble than the spectrum of didymium

The Phosphorescent Spectrum of Samarium.-Pure samaric sulphate by itself gives a very feeble phosphorescent spectrum. When, however, the samaria is mixed with lime before examination in the radiant matter tube, the spectrum is, if anything, more beautiful than that of yttrium. The bands are not so numerous, but the contrasts are sharper. Examined with a somewhat broad slit, and disregarding the fainter bands, which require care to bring them out, the spectrum is seen to consist of three bright bands-red, orange, and green-nearly equidistant, the orange being the brightest. With a narrower slit the orange and green bands are seen to be double, and on closer examination faint wings are seen, like shadows to the orange and green bands.

Preliminary experiments had shown me that lime was one of the best materials to mix with samaria in order to bring out its phosphorescent spectrum, but it was by no means the only body which would have the desired effect.

The samarium spectra, modified by other metals, may be divided into three groups. The first group comprises the spectra given when glucinum, magnesium, zinc, cadmium, lanthanum, bismuth, or antimony is mixed with the samarium. It consists simply of three coloured bands-red, orange, and green; as a typical illustration I will select the lanthanum-samarium spectra (Fig. I),

The second type of spectrum gives a single red and orange and a double green band. This is produced when barium, strontium, thorium, or lead are mixed with samarium. The lead-samarium spectrum (Fig. 2) illustrates this type.

The third kind of spectrum is given by calcium mixed with samarium. Here the red and green are single, and the orange double. Aluminium would also fall into this class were it not that the broad, ill-defined green band is also doubled. The calcium-samarium spectrum (Fig. 3) is a good illustration of this type.

Mixed Samarium and Yttrium Spectra.-It was interesting to ascertain what spectrum a mixture of samarium and yttrium would give. A mixture of go parts of samaria to Io of yttria was treated with sulphuric acid and then ignited, and afterwards examined in the radiant matter tube. 'The result was as remark able as it was unexpected. Not a trace of the yttrium spectrum could be detected. The powder phosphoresced with moderate intensity, but the spectrum was aluost the facsimile of that given by pure samaric sulphate, except that the sharp orange line, which in the spectrum of pure samaric sulphate is only just visible, had gained sufficiently in intensity to be measurable, and was found to lie at 2693 , on the $\frac{1}{\lambda^{2}}$ scale. A large number of experiments were next tried on mixtures of samaria and yttria in different proportions, and the results are given in full in the paper.

Up to mixtures of 43 parts samaria and 57 parts yttria the spectrum nearly resembled the lead-samarium spectrum. Not a band of the yttria spectrum could be detected, and the brilliant orange line stood out sharply in the whole series. This spectrum is represented in Fig. 4 .
After that proportion had been reached a change rapidly came over the spectra, and in the next trial mixture-samaria 35 , yttria 65-the only indication of the samarium spectrum that could now be found was seen in the two faint green bands next to the citron line of yttria, and the new orange line, which shone out as brightly and sharply as ever.

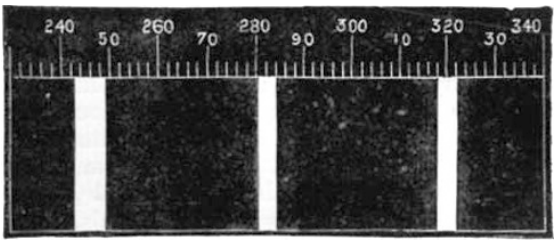

FIG. I.

It will be remarked that a sudden change of spectrum occurs between very narrow limits of mixture.

The spectrum of a mixture of 44 parts samaria and 56 parts yttria, except for the orange line, is the pure samarium spectrum. The spectrum of 42 samaria and 58 yttria is built up of some of the component bands of the spectrum of each earth ; whilst the

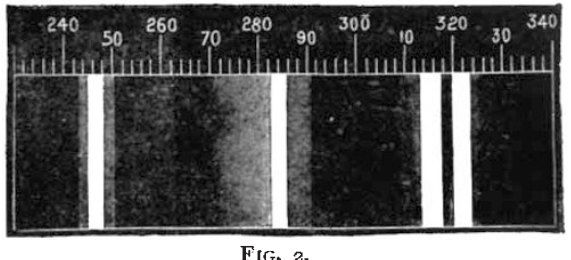

spectrum of 39 samaria and 61 yttria is almost a pure yttria spectrum, the sharp orange line running across them all.

The Delicacy of the Spectrum Test for Samarium.-Experiments were now commenced with the object of getting some approach to a quantitative estimate of how small a quantity of samarium could be detected.

A mixture was first made in the proportion of I part sama-

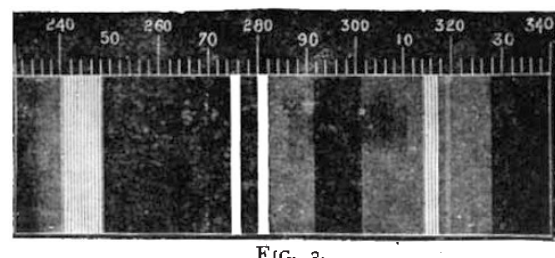

rium to 100 parts of calcium. The spectrum is very brilliant, and but little inferior in sharpness to, the spectrum given by a 5o per cent. mixture.

A mixture was now prepared containing I part of samarium to I000 parts of calcium. Very little difference can be detected between the spectrum of this mixture and that of the last. The bands are, however, a little less sharp.

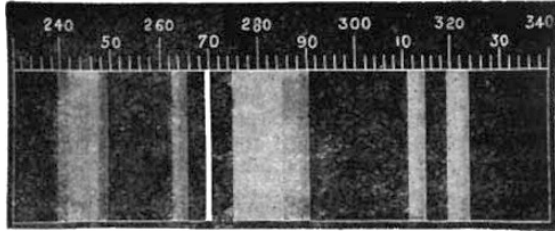

FIG. 4

A mixture containing I part of samarium to 10,000 parts o calcium was now tested. The bands are now getting fainter the second green band is fading out, and the continuous spectrum of calcic sulphate is getting brighter.

The next mixture tried contained one part of samarium ir I00,000 parts of calcium. Here the green is almost gone, bein overshadowed by the continuous spectrum of calcium which ha 
spread over it. The red band has likewise almost disappeared in the greater brightness of the continuous red of the calcic spectrum. The double orange band is still very prominent, and the black space, 2942, between it and the green is very marked.

The next mixture, one part of samarium to 500,000 parts of calcium, gives a spectrum which is fainter than the last, but the orange bands are still distinctly visible. The blank space between the yellow and green is strongly marked, but narrower than before.

A mixture of one part of samarium in $x, 000,000$ parts of calcium was next subjected to experiment. In this the samarium spectrum is very feeble, and the orange bands are only to be seen with difficulty. Now the most striking characteristic of this spectrum is the black space which still cuts out the greater portion of the yellow.

A mixture of one of samarium in 2,500,000 parts of calcium was now taken. In the spectrum shown by this mixture the bands of samarium have entirely gone, and its presence now is apparent only by the darkening in the yellow portion of what otherwise would be a continuous spectrum.

The calcium phosphorescent spectrum by itself is continuous, with no break, lines, or bands in it.

The Anomalous Line $\frac{\mathrm{I}}{\mathrm{N}^{2}} 2693 .-\mathrm{O}$-On several occasions I have spoken of an orange line, 2693 , which by its brilliancy and sharpness is a prominent object in most of the samarium-yttrium spectra. With pure samaric sulphate it is exceeding faint. With samaria containing 5 per cent. of yttria it is very little brighter; with ro per cent of yttria it gains a little; with 15 per cent. it is brighter still, and with a mixture of 80 parts samaria and 20 parts yttria it is at its maximum intensity. It continues to be the most striking feature in the spectra of the various mixtures of samaria and yttria until the proportion becomes samaria 3, yttria 97 , when it begins to get less bright, and only when pure yttria is reached does it altogether vanish.

It is noteworthy that so long as this bright line is a component of the spectrum, the other bands manifest decidedly less intensity, and many of them are suppressed. The profound modification in the spectra of samaria and yttria developed by their mixture is, I believe, without precedent in spectrum analysis. It is difficult to realise the character of the modification which converts somewhat faint diffused bands into one intensely sharp and brilliant line.

One important lesson taught by the many anomalies unearthed in these researches is that inferences drawn from spectrum analysis per se are liable to grave doubt, unless at every step the spectroscopist goes hand in hand with the chemist. Spectroscopy may give valuable indications, but chemistry must after all be the court of final appeal.

The following paper (reprinted from the Chemical Nezos) is so intimately connected with Mr. Crookes's work, that it may be appropriately appended to his paper :-

AT the meeting of the Académie des Sciences on June 8, I885, M. Lecoq de Boisbaudran requested that a sealed packet which he had deposited June 30,1884 , might be opened. The packet was opened by the Permanent Secretary during the meeting, and contained the following note :-

"When the electric spectrum of a solution with a metallic base is produced it is customary to make the outside platinum wire (whence the induction spark strikes) positive, the liquid consequently forming the negative pole. ${ }^{1}$ If the direction of the current is reversed, the metallic rays (due to the free metal or to one of its compounds) are scarcely or not at all visible, at at all events so long as the exterior platinum wire now forming the negative pole is not coated with a deposit.

"Having again last year taken up my researches on the rare earths belonging to the didymium and yttrium family, I had occasion to observe with many of my preparations the formation of spectrum bands, nebulous, but sometimes tolerably brilliant, having their origin in a thin layer of a beautiful green colour, which was seen to appear at the surface of the liquid (a solution of a chloride) when it was rendered positive.

"These are the approximate positions of the principal bands :-

T This rule, hitherto general for metallic solutions, is not always applicable to liquids containing metalloid bodies, as. I have already had occasion to notify (see my "Spectres Lumineux," p. 38 ).
Micrometer $91 \frac{3}{4}$

IOI
Approximately
about the middle.
104\% Approximately about the middle.

About the
middle.

\begin{tabular}{|c|c|}
\hline $\begin{array}{l}\text { From } \\
\text { II I } \frac{1}{2} \\
\text { to } \\
\text { I I } 2\end{array}$ & $\begin{array}{l}\text { About the be- } \\
\text { ginning. Very } \\
\text { indistinct. }\end{array}$ \\
\hline II $5 \frac{1}{5}$ & $\begin{array}{l}\text { About the mid- } \\
\text { dle of maximum } \\
\text { of light. }\end{array}$ \\
\hline II 7 & $\begin{array}{l}\text { About the end. } \\
\text { Very indistinct. }\end{array}$ \\
\hline $\begin{array}{c}\text { About } \\
\text { I4 } \text { I }^{\frac{1}{5}}\end{array}$ & $\begin{array}{l}\text { Apparent } \\
\text { centre. }\end{array}$ \\
\hline
\end{tabular}

\section{About ) I $47 \frac{1}{3}$
to $147 \frac{1}{2}$ Apparent
centre. centre.}

$\begin{array}{cc}\lambda & \text { Observations } \\ 620 \frac{1}{2} & \text { A narrow band, somewhat }\end{array}$ hazy. Rather faint. About $I \frac{1}{2}$ divisions wide. (Due to calcium??)

$585 \frac{3}{4} \quad$ A nebulous band slightly connected with the following one. About 3 divisions wide. Slight intensity, but generally stronger than $9 \mathrm{I} \frac{3}{4}$.

573 A nebulous band. Intensity varying with the state of the liquid and seems to be fainter in the earths obtained from the sulphates which are very slightly soluble in potassic sulobtained from the more soluble double sulphates. In some cases it has been seen as brilliant as $\alpha$ 1 $15 \frac{1}{5}$, but it has almost always been seen much more feeble than $115^{\frac{1}{5}}$ in the earth obtained from the very slightly soluble double sulphate. It has, indeed, on several occasions been seen fainter than IOI.

A nebulous band, shading off from right to left. Ratherstrong, and generally much the most brilliant in the spectrum of the yellow earth whose double potassic soluble.

487 A very hazy band, appearing somewhat shaded from right to left when About 4 or $4 \frac{1}{2}$ divisions wide. Somewhat joined to the following. Generally of very moderate intensity.

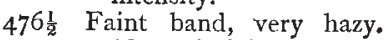
About 6 divisions wide. strength of spark. It phate than in the earths sulphate is very slightly the spectrum is brilliant.

"On comparing in the different products the relative intensities of this new reversion spectrum and of the already known direct rays, I have come to the conclusion that the boty producing the band $\alpha$ I I $5 \frac{1}{2}$ is very probably not one of the following :-

"Didymium, erbium, Ya (of M. de Marignac), lanthanum, samarium, zirconium, scandium, thulium, ytterbium, yttrium.

"Cerium and thorium are also excluded for chemical reasons.

"I have not yet obtained the new spectrum with a substance altogether free from holmium, but I have good reasons to think that this metal is not the cause of the observed phenomena.

" The treatment undergone by the earths which give most sharply the reversion spectrum hardly admits in my preparati ins of the presence of such bodies as phosphoric, boric, \&c., acids.

"The band $\alpha$ II $5 \frac{1}{5}$ (and most of the others which, except perhaps the band $104 \frac{9}{10}$, follow in their intensities the same variations as $\alpha \times 15 \frac{1}{5}$ ) appears, therefore, only to be attributable to terbia, unless, indeed, it be due to some new analogous earth not hitherto defined. ${ }^{1}$

"The treatment of a yellow earth obtained from samarskite, and much rescmbling that which is now called terbia, has already

I There remains to be examined the earth decipia (of M. Delafontaine), the existence of which appears to be confirmed by the researches of $M$.
Clève. 
given me interesting results, which, however, it will be difficult to describe in this short preliminary note. I will only say that all the bands specified above (except sometimes $104 \frac{9}{10}$ ) are especially very marked in the earth which is most easily precipitated by ammonia, which has a sulphate least soluble in potassic sulphate, and whose chloride, very soluble in pure water, is difficultly soluble in concentrated hydrochloric acid.

"Shall we find two earths respectively characterised by the bands IO $41_{10}^{9}$ and $\alpha$ II $5 \frac{1}{5}$ ?

"The production of my reversion spectrum appears to be analogous physically with the formation of the phosphorescence spectra obtained by Mr. Crookes at the positive pole in his high vacutum tubes containing certain compounds of yttria. The conditions of the two experiments are, however, very different practically speaking.

"It is a singular fact that the positions of the phosphorescence bands observed by Mr. Crookes with very pure compounds of yttrium, are sufficiently near those which $I$, on my part, have obtained with hydrochloric solutions of the earths separated as widely as possible from yttria, chemically as well as spectroscopically. My reversion spectrum cannot, I think, be attributed to yttrium, for on the one hand it is seen brilliantly with products which give no trace of yttrium rays by the direct spark, and on the other hand I have found it impossible to obtain it sharply from certain earths extremely rich in yttria.

"As soon as my work is sufficiently advanced to enable me to arrive at some definite conclusion, I shall have the honour of informing the Academy of it."

M. Lecoq de Boisbaudran added the following additional note :-

I have not yet finished the very long work undertaken in the hope of determining the nature of the above described phosphorescence spectrum.

This spectrum is now recognised as being identical with that which is ascribed to pure yttria by Mr. Crookes, and which this savant obtained under experimental conditions very different to mine. Nevertheless my latest observations, as well as the older ones, lead to the conclusion that yttria is not the cause of the spectrum bands observed. In my fractionations the phosphorescence spectrum regularly gets weaker as I advance towards the yttria end. With almost pure yttria the phosphorescence bands show themselves faintly or not at all, whilst they are brilliant with the earths which do not give by the direct spark the rays of yttrium to an appreciable extent.

The prodigious sensibility of Mr. Crookes's reaction, which detects a millionth part of his purified yttria, makes very singular this divergence which $I$ am obliged to point out between the conclusions of the eminent English chemist and myself. $\mathrm{Mr}$. Crookes has willingly undertaken to examine some of my products in his high-vacuum tubes; and, on the other hand, he has promised to send me the earths prepared by himself, so that I can examine them by my process. A comparison of these cross experiments, it is hoped, will throw some light on the question of the origin of the phosphorescence spectrum.

Another conclusion from my researches, a conclusion which I publish with a certain reserve because my work is not yet finished, is that the bands 105 and 115 do not belong to the same element. On this hypothesis, based on the fact that some of my products give 105 notably stronger than 115 , whilst others show 115 brightly and ro5 faintly, I will provisionally call $Z \alpha$ the earth characterised by 105 , and $Z \beta$ the earth giving 115 .

Space does not allow me to describe to-day the principal experiments or observations undertaken to find out what are $Z a$ and $Z \beta$; this will form the subject of another memoir.

I should acknowlèdge here that Mr. Crookes was the first to see the phosphorescence spectrum of samarium. During the past year only this spectrum was pointed out to me by my learned fitiend M. Demarçay, to whom I had confided the secret of my method for the production of phosphorescence spectra by the reversion of the induced current. I then made a drawing of it. Comptes Rendus, vol. c. p. I437, June 8, 1885.

\section{SOCIETIES AND ACADEMIES LONDON}

Chemical Society, June I8.-Dr. Hugo Müller, F.R.S., President, in the chair.-Messrs. Jos. F. Burnett and Harry M. Freear were formally admitted Fellows of the Society. - The following gentlemen were duly elected Fellows of the Society :-
Messrs. Harry Hasleit, Thomas Cradock Hepworth, Leonard de Koningh, Charles Langer, Arthur Richardson, James Sharp, James Pender Smith, James Spilsbury. - The following papers were read :-On the decomposition and genesis of hydrocarbons at high temperatures: I., the products of the manufacture of gas from petroleum, by Henry E. Armstrong and A. K. Miller, Ph.D. Having carried the examination of the various products of the decomposition of petroleum effected at high temperatures, in the manufacture of oil-gas (see paper in the Fournal of the Society of Chemical Industry, September, I884), as far as can usefully be done with the material originally dealt with, the authors now describe their methods and results; they remark, however, that these must be regarded as little more than preliminary, and that it will be necessary to repeat the investigation on a much larger scale, and to introduce new and improved methods. The products examined are ( $I$ ) the portion of the compressed gas which combines with bromine; (2) the liquid deposited during compression of the gas to about ten atmospheres; (3) the portion of the tar which is volatile in steam. (I) By far the chicf constituents of the mixture of bromides obtained by scrubbing the compressed gas by bromine are ethylene bromide and crotonylene tetrabromide, $\mathrm{C}_{4} \mathrm{H}_{6} \mathrm{Br}_{4}$; propyleae and butylene bromides have also been separated from it. The gas is practically free from hydrocarbons of the acetylene series capable of producing a precipitate in an ammoniacal cuprous solution. (2) The liquid deposited during compression of the gas is a complex mixture of olefines, of hydrocarbons of the $\mathrm{C}_{11} \mathrm{H}_{2 \mathrm{n}-2}$ series, and of benzenes. The presence in it of normal amylene, hexylene, and heptylene has been demonstrated by the study of the products of oxidation of the various fractions. It is saturated with crotonylene, and contains a considerable quantity of the next homologue, $\mathrm{C}_{5} \mathrm{H}_{8}$; this latter hydrocarion has not been previously described ; it boils at $45^{\circ}$, and yields a tetrabromide which crystallises from alcohol in long flat prisms melting at II $4^{\circ}$. All attempts to separate a hydrocarbon having the properties of Schorlemmer's hexoylene from the fraction boiling at $80^{\circ}-82^{\circ}$ have hitherto been unsuccessful, the statement previously made by one of the authors that this hydrocarbon was present having been based on determinations which have since been discovered to be faulty. The liquid deposited during compression of oil-gas is rich in benzene and toluene, but contains only traces of higher benzenes. (3) The steam distillate from the tar contains the less volatile hydrocarbons present in the liquid deposited during compression of the gas, together with a great variety of others. It is rich in hydrocarbons which are readily polymerised by sulphuric acid; these appear to be mainly members of the $\mathrm{C}_{\mathrm{n}} \mathrm{H}_{2 \mathrm{n}-2}$ series, such as Schorlemmer discovered in the light oils from cannel and boghead coal, and which yield no acid higher than acetic on oxidation. The three xylenes and mesitylene and pseudocumene are present in about the same relative proportions as in ordinary coal-tar ; but in addition, the oil-gas tar contains certainly one-probably two-higher members of the benzene series: the amount obtained has not been sufficient, however, to permit of the precise determination of its nature. A very considerable amount of naphthalene may be separated from the tar; benzenoid hydrocarbons of higher boiling point than napthalene have also been obtained in small quantity. A certain, although relatively small, amount of a complex mixture of saturated hydrocarbons has also been separated from the tar: the quantity of material at their disposal has not enabled the authors to separate these to their satisfaction, and in a state sufficiently approaching purity; they are inclined to believe, however, that the mixture does not consist of paraffins, but of hydrocarbons of the $\mathrm{C}_{n} \mathrm{H}_{2 n}$ series - such as form the chief constituents of Russian petroleum. The hydrocarbons mentioned are by no means the sole constitu. ents of the material examined, but merely those which have been proved to be present. The theoretical conclusions to be deduced from the results are in some respects interesting. It would appear that only normal olefines are present, and it is also remarkable that apparently this series is not represented by terms higher than heptylene. No true acetylenes bave been detected; the crotonylene obtained is either methylallene, $\mathrm{CH}_{3}{ }^{\circ} \mathrm{CH} \cdot{ }^{\circ}{ }^{\circ} \mathrm{CH}_{2}$, or dimethylene-ethane, $\mathrm{C}_{3} \mathrm{H}_{2}\left(\mathrm{CH}_{2}\right)_{2}$, and from their behaviour on oxidation it is probable that the homologous hydrocarbons are closely related to it. Hence it may be inferred that in the formation of hydrocarbons of the $\mathrm{C}_{n} \mathrm{H}_{n 2-2}$ serics at high tem. peratures from normal olefines of the formula $\mathrm{C}_{\mathrm{n}} \mathrm{H}_{2 \mathrm{n}}+1 \cdot \mathrm{CH} \cdot \mathrm{CH}_{2}$ two atoms of hydrogen are removed in such a way that the terminal $\mathrm{CH}_{3} \cdot \mathrm{CH}_{2}$ radicle in the formula becomes either 